\title{
Dual function of egg-covering in the Kentish plover Charadrius alexandrinus
}

\author{
Juan A. Amat ${ }^{\mathrm{a}, *}$, Rocío Monsa ${ }^{\mathrm{a}, \mathrm{b}}$ and José A. Masero ${ }^{\mathrm{c}}$ \\ ${ }^{a}$ Department of Wetland Ecology, Estación Biológica de Doñana (EBD-CSIC), \\ Calle Américo Vespucio s/n, E-41092 Sevilla, Spain \\ ${ }^{\mathrm{b}}$ Instituto de Biociências-Universidade de São Paulo, Departamento de Ecologia, Rua do \\ Matão, trav. 14, no 321, Cidade Universitária, São Paulo-SP, CEP: 05508-090, Brazil \\ ${ }^{\mathrm{c}}$ Grupo de Investigación en Biología de la Conservación, Área de Biología Animal, \\ Universidad de Extremadura, Avda. Elvas s/n, E-06071 Badajoz, Spain \\ *Corresponding author's e-mail address: amat@ebd.csic.es
}

Accepted 2 August 2012

\begin{abstract}
Many bird species take recesses during incubation, and while the nests are unattended, the eggs may both be vulnerable to predation and reach suboptimal temperatures for embryo development. Perhaps to avoid these negative possibilities, some birds cover their eggs with materials when they depart from nests. We examined experimentally, using the ground-nesting Kentish plover as model species, whether egg-covering allows egg temperatures to remain within optimal limits for embryogenesis in unattended nests, thus reducing the requirements of contact incubation, and simultaneously maintain the eggs' camouflage. There was a negative relationship between nest attendance and ambient temperature, but only during mid-morning, the period of the day when eggcovering was most frequent. Indeed, during mid-morning egg-covering not only served to better camouflage the eggs, but also to maintain egg temperatures within optimal thermal thresholds for embryogenesis while the nests remained unattended. During other periods of the day, covered eggs in unattended nests overheated (e.g., afternoon) or did not reach the optimal temperature for embryogenesis (e.g., early morning). During periods in which eggs may be uncovered to alleviate overheating, unattended nests may be easier to locate by predators, because the eggs are less well camouflaged. Therefore, camouflage and appropriate thermal environment are inseparable functions of egg-covering in the ground-nesting Kentish plover.
\end{abstract}

\section{Keywords}

egg burial, egg crypsis, incubation, nest attendance, shorebirds, thermal environment. 


\section{Introduction}

Incubation is the process by which eggs are kept at temperatures suitable for embryonic development, which in the case of birds are generally between 37 and $38^{\circ} \mathrm{C}$, with most of the heat being provided by the incubating bird (Deeming, 2002). In birds, only the megapodes do not practice contact incubation to provide heat to their eggs, but instead bury the eggs in mounds of vegetation; these mounds receive considerable attention by males to maintain the appropriate incubation temperatures (Booth \& Jones, 2002). Burrow nesting crab plovers Dromas ardeola rely to a great extent on solar assisted incubation (de Marchi et al., 2008). The needs of incubation may impose energetic costs on parents (Williams, 1996), and may also limit the time that they may spend away from nests in other activities necessary for self-maintenance, such as foraging (Reid et al., 2002b; Creswell et al., 2004; Weston \& Elgar, 2005).

Many bird species take recesses during incubation, mainly to forage. However, leaving clutches unattended may have direct and immediate fitness costs through either suboptimal embryonic conditions and/or increased predation. Unattended nests may result in embryos diverging rapidly from developmental optima (Reid et al., 2002b). Because of this, off-bout duration is constrained by the optimal thermal needs of embryos, and particularly at both low and high ambient temperatures birds spend less time off the nest because at such temperatures embryo development is negatively affected (Conway \& Martin, 2000; Weston \& Elgar, 2005). As pointed out by Reid et al. (2002b), birds may reduce the requirements of incubation to some extent, for example by choosing nest materials based on their thermal quality (e.g., Hoi et al., 1994; Reid et al., 2002a; Mayer et al., 2009). Further, unattended eggs may be more vulnerable to predation, either because the incubating adults do not defend them, or because nests are easier to locate by predators (e.g., Remeš, 2005; Trnka et al., 2008; but see Brennan, 2010).

Some birds cover their eggs with materials when they depart from the nests. Egg-covering has also been recorded in both invertebrate and other vertebrate species (e.g., Keller, 1989; Shimoda et al., 1994; Villemart, 2001; Pérez-Santigosa et al., 2003; Opermanis, 2004; Kreisinger \& Albrecht, 2008), and two non-mutually exclusive main functions have been attributed to this behaviour: camouflage of the nest and/or maintenance of egg temperature (Maclean, 1974; Haftorn \& Slagsvold, 1995; for other functions of egg-covering see Sealy, 1995; Valera et al., 1997; Guigueno \& Sealy, 
2009). Therefore, under conditions of appropriate thermal environment and camouflage, egg-covering may be a mechanism with which birds reduce the requirements of contact incubation, allowing the incubating adults to spend more time in other activities, such as foraging (Howell, 1979; Davis et al., 1984). Consequently, there is likely to be selection for egg-covering if this allows the maintenance of an appropriate thermal environment for eggs in unattended nests, enabling adults to spend time away from nests in other activities necessary for self-maintenance.

Most studies on birds have interpreted egg-covering as an anti-predation tactic (Summers \& Hockey, 1981; Keller, 1989; Kreisinger \& Albrecht, 2008; Prokop \& Trnka, 2011), and few studies have addressed the effects of egg-covering on egg temperature, or whether egg-covering may reduce the requirements of contact incubation (Howell, 1979; Grant, 1982).

In birds, egg-covering is particularly common among shorebirds (Charadrii) breeding in hot and arid environments (Maclean, 1974; Grant, 1982). Optimal egg temperature for embryo development in most Charadriiformes is $35-38^{\circ} \mathrm{C}$ (Drent, 1975 ; Grant, 1982; Rahn, 1991). Many shorebird species nest on small scrapes on the ground, in sites with little or no cover (Grant, 1982; Koivula \& Rönkä, 1998; Brown \& Downs, 2003; Amat \& Masero, 2004a; AlRashidi et al., 2011), in which unattended nests may be easy to locate by visual searching predators and, thus, egg-covering may make the nests better camouflaged than if eggs remain uncovered (Summers \& Hockey, 1981). On the other hand, if the function of egg-covering is to maintain an optimal thermal environment for embryos, then egg-covering should occur when it allows egg temperatures to be within those limits, i.e., 35$38^{\circ} \mathrm{C}$, and should be avoided if it does not contribute to keep egg temperature within optimal limits for embryogenesis. These two main functions may not be mutually exclusive, however, as egg-covering may help to maintain nest camouflage and at the same time may serve to keep egg temperatures within more appropriate limits for embryogenesis than if eggs remain uncovered and unattended by adults. In addition, if egg-covering contributes to reduce the requirements of contact incubation, during periods in which eggs are covered there should be a negative relationship between ambient temperature and nest attendance by adults. We tested these predictions using the Kentish plover Charadrius alexandrinus as a model species, by analyzing the effects of egg-covering on egg temperatures, and quantifying the degree of egg camouflage in nests with both covered and uncovered eggs. We then used data on 
average ambient temperatures at our study site to explain why egg-covering was more frequent during particular periods of the day.

\section{Methods}

\subsection{Study species}

Our study was conducted at Fuente de Piedra Lake in southern Spain, described in Amat et al. (1999). Kentish plovers are small-sized shorebirds that nest on the ground and partially cover their eggs with nest materials (George Kainady \& Al-Dabbagh, 1976; Grant, 1982; Orr, 1999; Figure 1). Both sexes participate in incubation, with females practicing most diurnal incubation and males mainly incubating at night (Nazakawa, 1979; Fraga \& Amat, 1996; Kosztolányi \& Székely, 2002; Amat \& Masero, 2004b; AlRashidi et al., 2011). The main visual searching nest predator at our study site is the gull-billed tern Gelochelidon nilotica (Fraga \& Amat, 1996; Amat \& Masero, 2004a).

\subsection{Diurnal variations in egg-covering}

To record variations in egg-covering according to time of day we visited nests, under clear-sky conditions, around early morning (5:30 h GMT), midmorning $(9: 30 \mathrm{~h})$, mid-afternoon $(15: 00 \mathrm{~h})$, and late afternoon (18:30 h). When eggs were partially covered, we marked, using permanent pencil, the eggshell at the point at which the egg contacted with nest materials along the longest egg axis perpendicular to the ground (Figure 2). We then carefully
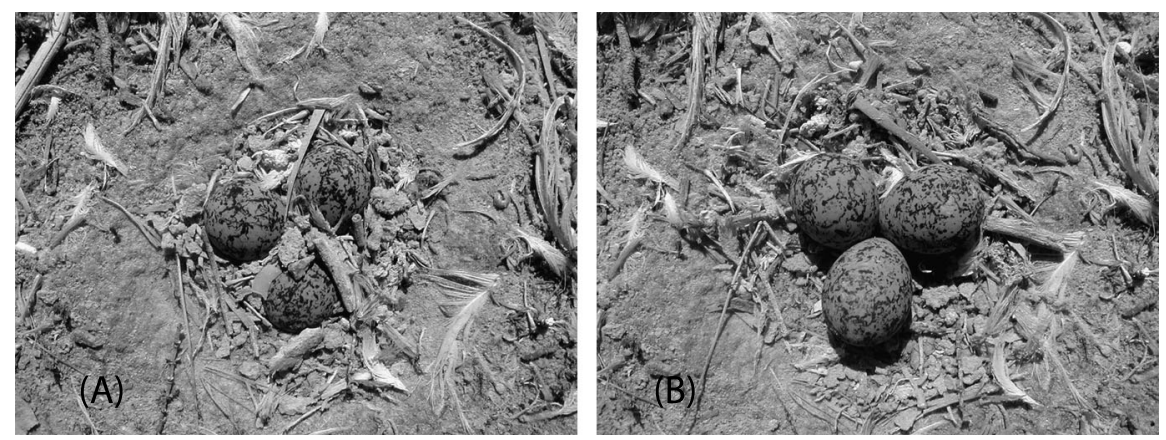

Figure 1. A Kentish plover nest with partially covered (A) and uncovered (B) eggs (photographs by José A. Masero). 


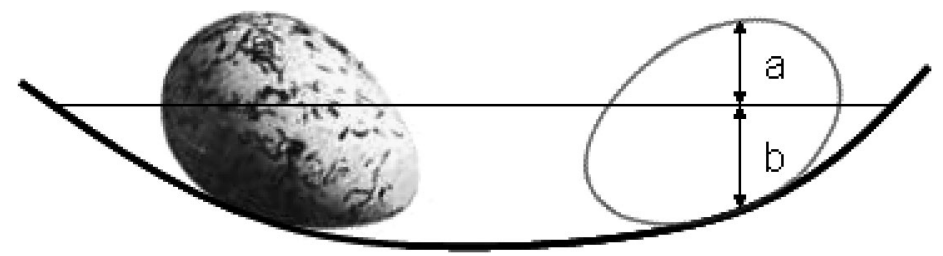

Figure 2. Schematic representation of the mode in that egg-covering was measured. The length of the part of the longest egg axis perpendicular to the ground that was uncovered with materials $(a)$ was measured to the nearest $0.1 \mathrm{~mm}$ using digital calipers, as well as the length of that axis $(a+b)$. The degree of egg-covering was expressed as $(a /(a+b)) \times 100$.

removed the egg from the nest while maintaining that longest axis perpendicular to the ground. Using digital callipers, one of us (always the same) measured to the nearest $0.1 \mathrm{~mm}$ the length of that axis, as well as the length of the part of the axis that was uncovered with materials. After this, we left the eggs in a state of covering similar to which we had found them. The procedure took 3-5 min. The degree of egg-covering was expressed as the length of the part of the axis that remained covered relative to total axis length (Figure 2), and this was expressed as percentage. Therefore, egg-covering may vary between 0 (egg completely uncovered) and 100 (egg completely covered). We took these measurements for every egg in 15 nests, and then averaged these values for each nest.

\subsection{Egg-covering and nest camouflage}

To evaluate whether egg-covering rendered the nests more cryptic, we photographed Kentish plover nests, using an Olympus C900Z camera. Photographs were taken approximately $30 \mathrm{~cm}$ above the nests, under clear-sky conditions, between 9:00 and 11:00 h (GMT). We chose this period because during previous studies we noticed that such period was when the eggs were more frequently covered with materials (see below). A photograph of each nest was taken with eggs partially covered, and immediately after this we removed the materials that partially covered eggs and took a second photograph with eggs uncovered.

In such photographs, we quantified the coloration of eggs and nest scrape with Adobe Photoshop CS4 (Adobe, San José, CA, USA). The eyedropper was set at $51 \times 51$ pixels, with a resolution of 72 pixels/inch, and values in the $L^{*} a^{*} b^{*}$ colour space were recorded (see Nguyen et al., 2007; Pereira $\&$ Amat, 2010), where $L^{*}$ defines lightness, $a^{*}$ denotes the red/green value 
and $b^{*}$ the yellow/blue value (X-Rite, 2000). We took readings at spaced points on the images, noting whether the readings were on eggs or nest scrape. Five metric values were obtained for each category (egg, nest scrape), which were averaged for each one of these categories for each photograph. Colour differences $\left(\Delta E^{*}\right)$ between eggs and nest scrape were defined by the equation (X-Rite, 2000)

$$
\Delta E^{*}=\left(\Delta L^{* 2}+\Delta a^{* 2}+\Delta b^{* 2}\right)^{1 / 2} .
$$

The larger $\Delta E^{*}$, the lower the similarity in coloration between eggs and nest scrapes.

\subsection{Nest attendance}

We set up blinds 15-20 m from 13 nests to record nest attendance by adults. We made observations during 2-h periods in the early morning (04:3006:30 h, GMT), mid-morning (08:00-10:00 h), mid-afternoon (14:0016:00 h) and late afternoon (17:00-19:00 h). An observation started when adults returned to nests after we had entered the blinds. The birds resumed incubation $15.9 \pm 11.14 \mathrm{~min}$ (average $\pm \mathrm{SD}$; range $=2-49 \mathrm{~min}, n=32$ observations at 13 nests) after we entered the blinds. We considered nest attendance as the percentage of time that the nest was attended by an adult, either male or female, relative to total observation time, and related nest attendance to ambient temperature, which was recorded every $40 \mathrm{~s}$ as indicated below, and averaged for each of the observation periods.

All nests were not in a similar stage of incubation when we conducted the observations. Nevertheless, our results were not likely affected by this, since nest attendance in plovers is not affected by clutch's age (Weston \& Elgar, 2005; O. Vincze et al., unpubl.).

\subsection{Eggs and ambient temperatures}

To ascertain how egg-covering affected egg temperatures, we performed an experiment on sunny days. For this, we used Kentish plovers eggs previously collected from deserted nests. These eggs were emptied and filled with plaster of Paris, which has a thermal conductance almost identical to that of natural eggs (see Ward, 1990; Amat \& Masero, 2007). We placed a model egg in each of 25 empty nests of plovers that were in sites exposed to direct solar radiation. We partially covered with materials one model egg, with a degree of coverage similar to that found in natural nests, and left it shaded 
for $3 \mathrm{~min}$, after which we removed the shade and left the egg exposed to direct solar radiation during $10 \mathrm{~min}$. After this, we shaded the egg again during $3 \mathrm{~min}$, and while the egg was shaded we removed the partial covering of nest materials. Finally, we removed the shade and left the egg exposed for another $10 \mathrm{~min}$. We recorded the maximum temperature reached by model eggs during the 10-min periods. The order of treatment of model eggs (first covered, then uncovered, or vice versa) was arbitrary. We used eight model eggs.

Temperatures of model eggs ( $\left.T_{\text {egg }}\right)$ were recorded with 36-gauge copperconstantan thermocouple probes (Omega Engeneering, Stamford, CT, USA) inserted into the eggs. Ambient temperature $\left(T_{\mathrm{a}}\right)$ was measured at an exposed site about $1 \mathrm{~m}$ from nests, and $5 \mathrm{~cm}$ above ground level, using a 20-gauge copper-constantan thermocouple probe, with its tip covered with white reflective tape (Ward, 1990). All probes were connected to Omega OM-550 dataloggers, which were programmed to record temperatures every $40 \mathrm{~s}$.

\section{Results}

\subsection{Diurnal variations in egg-covering}

The degree of egg-covering varied throughout the day, being greater during mid-morning (Figure 3, Friedman ANOVA, $\chi_{3}^{2}=15.6, N=15, p=0.001$ ). Although there was also some degree of covering at other times of day, it was very small and it seemed that this was due to the eggs being slightly depressed in the nest materials rather than to a true egg-covering.

\subsection{Egg-covering and camouflage}

The difference in coloration $\left(\Delta E^{*}\right)$ between eggs and nests was lower in nests with partially covered eggs (mean \pm SD $7.6 \pm 4.04, N=8$ ) than in the same nests with eggs uncovered $(15.0 \pm 6.57)$ (Student's paired $t$-test, $t=3.20, \mathrm{DF}=7, p=0.015)$. Therefore, the eggs were better camouflaged when they were covered.

\subsection{Nest attendance and temperatures}

There was a negative relationship between the percent of time incubating and $T_{\mathrm{a}}$ during mid-morning (Figure 4, $r=-0.64, N=12, p=0.027$ ), but not during the rest of the day $(r=0.06, N=13, p=0.836)$. 


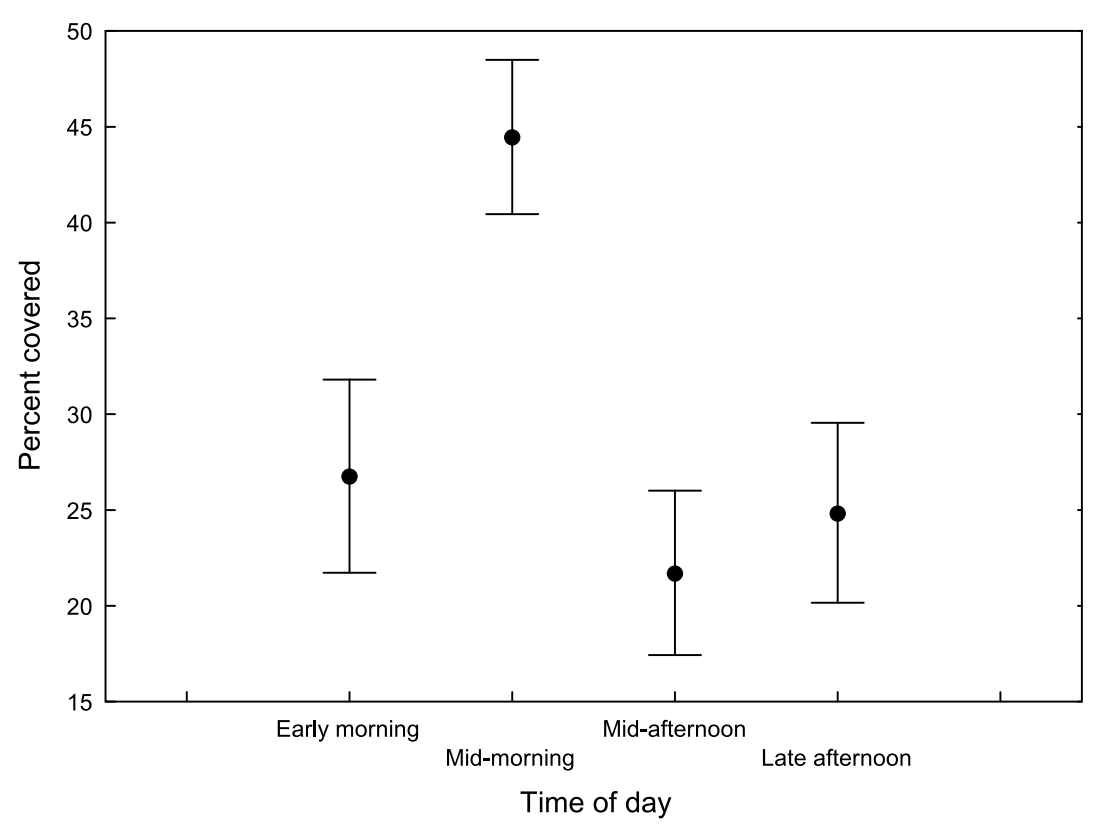

Figure 3. Diurnal variations in the mean degree of egg-covering $( \pm \mathrm{SE})$ in 15 Kentish plover nests.

\subsection{Egg-covering and temperatures}

Ambient temperatures explained a large proportion of the variance in $T_{\text {egg }}$, both in uncovered $\left(r^{2}=0.85, N=25, p<0.001\right)$ and covered model eggs $\left(r^{2}=0.89, N=25, p<0.001\right)$. However, the slope of the relationship between both variables was steeper in covered than in uncovered model eggs (Figure $5 ; F_{1,46}=8.4, p=0.006$ ), meaning that at high temperatures covered eggs gained temperature at higher rate than uncovered nests $\left(F_{1,46}=\right.$ 5.7, $p=0.022$ ).

To reveal why egg-covering is more frequent during mid-morning than during other periods of the day, we used data on diurnal average $T_{\mathrm{a}}$ at our study site (Amat \& Masero, 2004b), together with the equations relating $T_{\mathrm{a}}$ and $T_{\text {egg }}$ in nests with covered and uncovered eggs (Figure 5). According to these equations, for unattended uncovered eggs, $T_{\text {egg }}$ would be optimal for embryogenesis $\left(35-38^{\circ} \mathrm{C}\right)$ at $T_{\mathrm{a}} 28.7-32.3^{\circ} \mathrm{C}$. On the other hand, for unattended covered eggs, $T_{\text {egg }}$ would be optimal for embryogenesis at $T_{\mathrm{a}}$ $28.0-30.5^{\circ} \mathrm{C}$. This range of $T_{\mathrm{a}}\left(28.0-32.3^{\circ} \mathrm{C}\right)$ is usually found during midmorning (Figure 1 in Amat \& Masero, 2004b), which is the period in which 


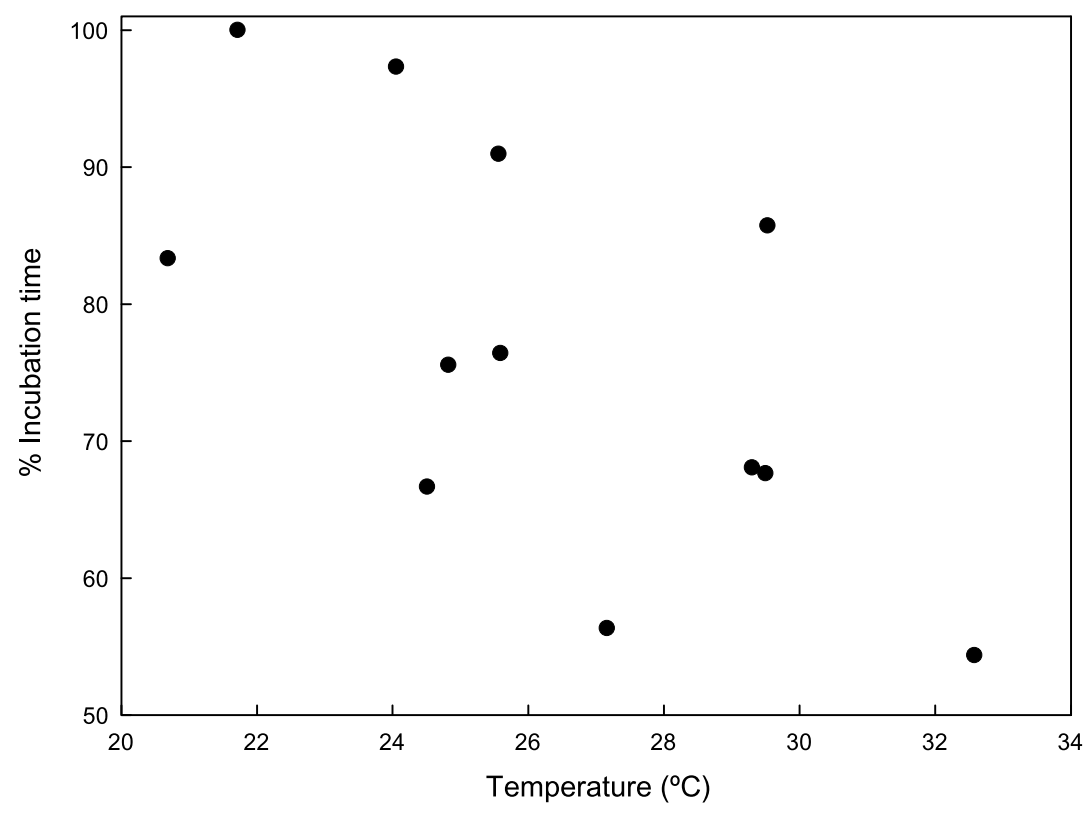

Figure 4. Percent time spent incubating by Kentish plovers in relation to ambient temperature during mid-morning (08:00-10:00 h).

the eggs remain more frequently covered (Figure 3). During average conditions in the morning at Fuente de Piedra, it takes $74 \min$ for $T_{\mathrm{a}}$ to rise from 28.7 to $32.3^{\circ} \mathrm{C}$ (after Figure 1 in Amat \& Masero, 2004b). It takes $51 \mathrm{~min}$ for $T_{\mathrm{a}}$ to rise from 28.0 to $30.5^{\circ} \mathrm{C}$ in the morning, i.e., the period in which unattended eggs encounter optimal thermal conditions for embryogenesis during the morning may be extended for 23 min when eggs are uncovered relative to when eggs are covered.

At average $T_{\mathrm{a}}$ at Fuente de Piedra (Figure 1 in Amat \& Masero, 2004b) during other periods of the day, $T_{\text {egg }}$ in covered unattended nests was not optimal for embryogenesis, according to equation in Figure 5 for covered eggs, either in the early morning $\left(T_{\mathrm{egg}}<28.0^{\circ} \mathrm{C}\right)$ or in the mid-afternoon $\left(T_{\text {egg }}>43.8^{\circ} \mathrm{C}\right)$. However, in the late afternoon, $T_{\text {egg }}$ in unattended covered nests would be $37.5^{\circ} \mathrm{C}$, which is within the optimal range for embryogenesis. Therefore, these results explain why eggs are not covered in the early morning or mid-afternoon, because during such periods eggs in unattended covered nests do not achieve appropriate conditions for embryogenesis. But these results do not explain why eggs are not covered in the late afternoon, 


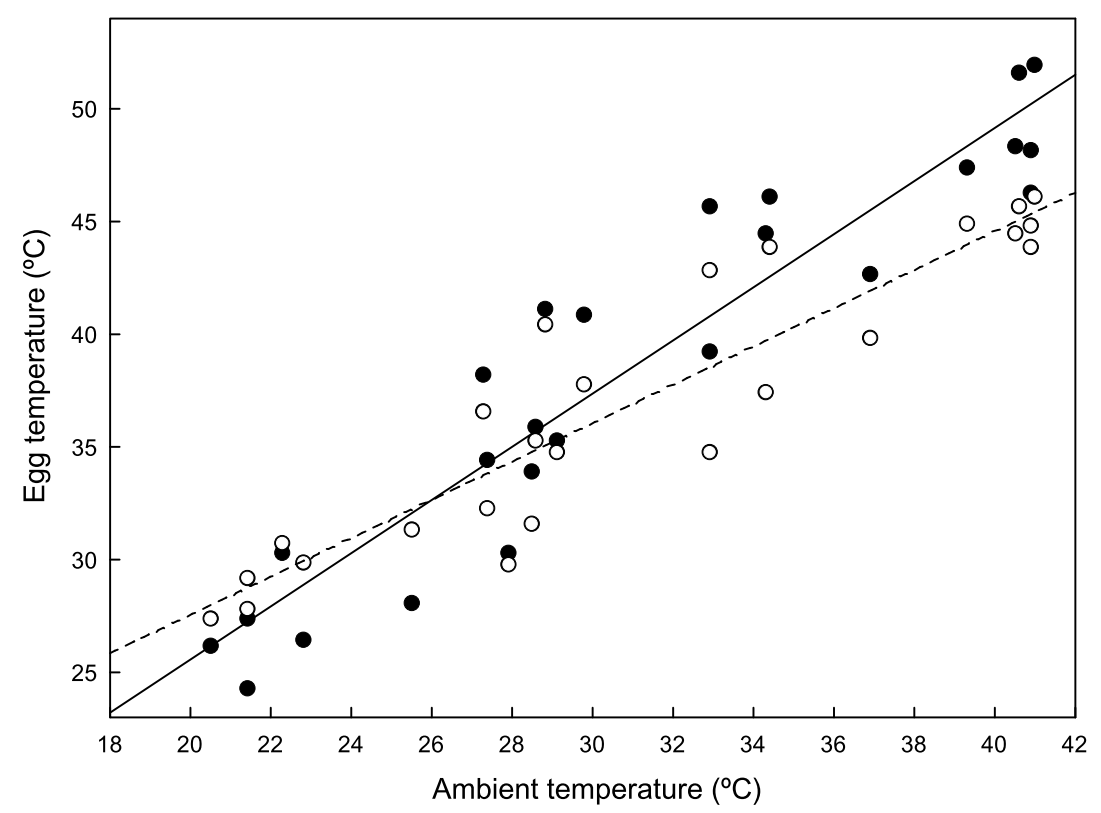

Figure 5. Linear relationships between egg and ambient temperatures in covered (filled circles, solid line) and uncovered Kentish plover nests (open circles, dashed line). Regression line for uncovered eggs: Egg temperature $\left({ }^{\circ} \mathrm{C}\right)=10.5469+0.8504 \times$ Ambient temperature $\left({ }^{\circ} \mathrm{C}\right)$. Regression line for covered eggs: Egg temperature $\left({ }^{\circ} \mathrm{C}\right)=1.9840+1.1793 \times$ Ambient temperature $\left({ }^{\circ} \mathrm{C}\right)$.

since in this period unattended covered eggs would result in optimal thermal conditions for embryogenesis.

\section{Discussion}

Our results show that egg-covering in the Kentish plover mainly serves to make the eggs more cryptic, while also aiding to maintain egg temperature within optimal thresholds while the nests remain unattended. Consequently, the function of egg-covering in the Kentish plover is dual. But these two functions (camouflage and appropriate thermal environment) have to act simultaneously to be effective. For such reason, the time window during which egg-covering is functional is rather narrow. Indeed, our findings suggest that the time that adults could spend off the nests is constrained by the critical thermal conditions that covered eggs experience when $T_{\mathrm{a}}>30.5^{\circ} \mathrm{C}$, which would be alleviated by uncovering eggs until $T_{\mathrm{a}}$ reaches $32.3^{\circ} \mathrm{C}$, but then the eggs in unattended nests would be more vulnerable to predators, as they 
are less cryptic. This is the reason for which both functions would have to act simultaneously to be effective, thus precluding the use of egg-covering during some periods of the day. This may be so during the early morning because $T_{\text {egg }}$ in unattended covered nests is below the range for optimal embryo development, or during the mid-afternoon, when unattended covered eggs overheat. Nevertheless, eggs in unattended covered nests would find optimal conditions for embryogenesis during the late afternoon, yet the eggs are not usually covered during this period. A reason for this may be that at such time male and female Kentish plovers shift incubation (Fraga \& Amat, 1996), and there would be no need to cover the eggs for a better camouflage because the nest would not remain unattended. Similarly, in other studies it was found that eggs were only covered in the morning (Liversidge, 1965; George Kainady \& Al-Dabbagh, 1976; Howell, 1979; but see Clark, 1982).

Previous studies on invertebrates and vertebrates have concluded that facultative egg-covering renders the clutches better camouflaged (Summers \& Hockey, 1981; Keller, 1989; Shimoda et al., 1994; Opermanis, 2004; Kreisinger \& Albrecht, 2008). Prokop \& Trnka (2011) also found that, in the laboratory, cooling rates were higher in grebe nests with uncovered eggs than in nests with covered eggs. However, few studies examined how the interaction between egg-covering and thermal environment may affect egg temperatures suitable for embryogenesis (Howell, 1979; Grant, 1982).

Clark (1982) and Szentirmai \& Székely (2004) concluded that, in plover nests with covered eggs, nest material could shade the eggs during parental absences from the nests, thus preventing the eggs from overheating. However, Grant (1982) showed experimentally that during the hottest part of the day even shaded eggs buried partially or totally at shallow depths in dry sand would be fatally overheated. Because neither Clark (1982) nor Szentirmai \& Székely (2004) presented data on egg temperatures, their conclusions are difficult to assess. In fact, Howell (1979) noted that in the Egyptian plover Pluvianus aegyptius temperatures of covered eggs remained within safe limits as solar heat was moderate during periods when nests were unattended, and that adult birds returned to nests when heat became intense (see also Weston \& Elgar, 2005).

As predicted by Conway \& Martin (2000) for birds attending nests, offbout duration was longer during periods in which the thermal needs of embryos were more favourable. This may facilitate that, during such periods, birds are released from contact incubation and, therefore, may spend more time foraging (Weston \& Elgar, 2005). Indeed, we found that when $T_{\mathrm{a}}$ was 
$27-32^{\circ} \mathrm{C}$ the adults spent $12-55 \%$ off the nests (Figure 4 ). At such $T_{\mathrm{a}}, T_{\text {egg }}$ in unattended covered nests would vary between 33.8 and $39.7^{\circ} \mathrm{C}$, a range that encompasses the optimal temperatures for embryo development. Such ambient temperatures are usually found during mid-morning (Figure 1 in Amat $\&$ Masero, 2004b), the period in which the eggs remain more frequently covered. During the thermal conditions of mid-morning the eggs may be left unattended for longer periods when uncovered than when covered. However, during these periods in which the eggs may be uncovered to alleviate overheating, unattended nests may be easier to locate by predators (Keller, 1989; Opermanis, 2004; Prokop \& Trnka, 2011), because the eggs are less well camouflaged. As shorebirds suffer high nest predation rates (e.g., Fraga \& Amat, 1996; Neuman et al., 2004; Saalfeld et al., 2011), better egg camouflage may be adaptive because this may improve nesting success (Solís \& de Lope, 1995; Lee et al., 2010; Colwell et al., 2011).

Previous work on the adaptive value of egg-covering has been mainly aimed at studying the effects of egg concealment on egg survival, and to a lesser extent on egg temperatures. However, as egg-covering also allows birds to reduce the requirements of contact incubation, to fully understand the adaptive value of this behaviour, future studies should also consider its direct effects on the incubating adults (e.g., by analyzing changes in their body condition).

\section{Acknowledgements}

Financial support was received from research projects PB95-0110 from Dirección General de Investigación Científica y Técnica and CGL2011-24230 from Ministerio de Ciencia e Innovación, Spain, both with EU-ERDF financial support. The Consejería de Medio Ambiente of the Junta de Andalucía authorized our study and provided many facilities. Thanks to Manuel Rendón-Martos, director of the Fuente de Piedra Nature Reserve, for so many facilities. José Luis Arroyo and Manuel Vázquez assisted in the field work. We also appreciate the comments of anonymous referees and Associate Editor Dr. Ken A. Otter on previous versions.

\section{References}

AlRashidi, M., Kosztolányi, A., Shobrak, M., Küpper, C. \& Székely, T. (2011). Parental cooperation in an extreme hot environment: natural behaviour and experimental evidence. - Anim. Behav. 82: 235-243. 
Amat, J.A. \& Masero, J.A. (2004a). Predation risk on incubating adults constrains the choice of thermally favourable sites in a plover. - Anim. Behav. 67: 293-300.

Amat, J.A. \& Masero, J.A. (2004b). How Kentish plovers, Charadrius alexandrinus, cope with heat stress during incubation. - Behav. Ecol. Sociobiol. 56: 26-33.

Amat, J.A. \& Masero, J.A. (2007). The functions of belly-soaking in Kentish plovers Charadrius alexandrinus. - Ibis 149: 91-97.

Amat, J.A., Fraga, R.M. \& Arroyo, G.M. (1999). Brood desertion and polygamous breeding in the Kentish plover Charadrius alexandrinus. — Ibis 141: 596-607.

Booth, D.T. \& Jones, D.N. (2002). Underground nesting in the megapodes. — In: Avian incubation: behaviour, environment, and evolution (Deeming, D.C., ed.). Oxford University Press, Oxford, p. 192-206.

Brennan, P.L.R. (2010). Clutch predation in great tinamous Tinamus major and implications for the evolution of egg color. - J. Avian Biol. 41: 419-426.

Brown, M. \& Downs, C.T. (2003). The role of shading behaviour in the thermoregulation of breeding crowned lapwings (Vanellus coronatus). — J. Thermal Biol. 28: 51-58.

Clark, A. (1982). Some observations on the breeding behaviour of Kittliz's sandplover. Ostrich 53: 120-122.

Colwell, M.A., Meyer, J.J., Hardy, M.A., McAllister, S.E., Transou, A.N., Levalley, R.R. \& Dinsmore, S.J. (2011). Western snowy plovers Charadrius alexandrinus nivosus select nesting substrates that enhance egg crypsis and improve nesting success. - Ibis 153 : 303-311.

Conway, C.T. \& Martin, T.E. (2000). Effects of ambient temperature on avian incubation behavior. - Behav. Ecol. 11: 178-188.

Cresswell, W., Holt, S., Reid, J.M., Whitfield, D.P., Mellanby, R.J., Norton, D. \& Waldron, S. (2004). The energetic costs of egg heating constrain incubation attendance but do not determine daily energy expenditure in the pectoral sandpiper. - Behav. Ecol. 15: 498507.

Davis, T.A., Platter-Reiger, M.F. \& Ackerman, R.A. (1984). Incubation water loss by piedbilled grebe eggs: adaptation to a hot, wet nest. — Physiol. Zool. 57: 384-391.

Deeming, D.C. (2002). Importance and evolution of incubation in avian reproduction. - In: Avian incubation: behaviour, environment, and evolution (Deeming, D.C., ed.). Oxford University Press, Oxford, p. 1-7.

de Marchi, G., Chiozzi, G. \& Fasola, M. (2008). Solar incubation cuts down parental care in a burrow nesting tropical shorebird, the crab plover Dromas ardeola. — J. Avian Biol. 39: 484-486.

Drent, R.H. (1975). Incubation. — In: Avian biology, Vol. 5 (Farner, D.S., King, J.R. \& Pakes, K.C., eds). Academic Press, New York, NY, p. 333-420.

Fraga, R.M. \& Amat, J.A. (1996). Breeding biology of a Kentish plover (Charadrius alexandrinus) population in an inland saline lake. - Ardeola 43: 69-85.

George Kainady, P.V. \& Al-Dabbagh, K.Y. (1976). Some observations on the behaviour of incubating Charadrius alexandrinus on hot summer days. - Bull. Basrah Nat. Hist. Mus. 3: 121-137. 
Grant, G.S. (1982). Avian incubation: egg temperature, nest humidity, and behavioral thermoregulation in a hot environment. - Ornithol. Monogr. 30: 1-75.

Guigueno, M.F. \& Sealy, S.G. (2009). Nest sanitation plays a role in egg burial by yellow warblers. - Ethology 115: 247-256.

Haftorn, S. \& Slagsvold, T. (1995). Egg-covering in birds: description of the behaviour in tits (Parus spp.) and a test of hypotheses of its function. - Fauna Norv. Ser. C: Cinclus 18: 85-106.

Hoi, H., Schleicher, B. \& Valera, F. (1994). Female mate choice and nest desertion in penduline tits, Remiz pendulinus: the importance of nest quality. - Anim. Behav. 48: 743-746.

Howell, T.R. (1979). Breeding biology of the Egyptian plover, Pluvianus aegypticus (Aves: Glareolidae). - Univ. California Publ. Zool. 104: 1-76.

Keller, V. (1989). Egg-covering behaviour by great crested grebes Podiceps cristatus. Ornis Scand. 20: 129-131.

Koivula, K. \& Rönkä, A. (1998). Habitat deterioration and efficiency of antipredator strategy in a meadow-breeding wader, Temminck's stint (Calidris temminckii). — Oecologia 116: 348-355.

Kosztolányi, A. \& Székely, T. (2002). Using a transponder system to monitor incubation routines of snowy plovers. - J. Field Ornithol. 73: 199-205.

Kreisinger, J. \& Albrecht, T. (2008). Nest protection in mallards Anas platyrhynchos: untangling the role of crypsis and parental behaviour. — Funct. Ecol. 22: 872-879.

Lee, W.S., Kwon, Y.S. \& Yoo, J.C. (2010). Egg survival is related to the colour matching of eggs to nest background in black-tailed gulls. - J. Ornithol. 151: 765-770.

Liversidge, R. (1965). Egg covering in Charadrius marginatus. — Ostrich 36: 59-61.

Maclean, G.L. (1974). Egg-covering in the Charadrii. — Ostrich 45: 167-174.

Mayer, P.M., Smith, L.M., Ford, R.G., Watterson, D.C., McClutchen, M.D. \& Ryan, M.R. (2009). Nest construction by a ground nesting bird represents a potential trade-off between egg crypticity and thermoregulation. - Oecologia 159: 893-901.

Nakazawa, R. (1979). Incubation behaviour of the Kentish plover, Charadrius alexandrinus, with special reference to the share of the sexes and of effect ground surface temperature. - Misc. Rep. Yamashina Inst. Ornithol. 11: 54-63 (in Japanese, with English summary).

Neuman, K.K., Page, G.W., Stenzel, L.E., Warriner, J.C. \& Warriner, J.S. (2004). Effect of mammalian predator management on snowy plover breeding success. - Waterbirds 27 : 257-263.

Nguyen, L.P., Nol, E. \& Abraham, K.F. (2007). Using digital photographs to evaluate the effectiveness of plover egg crypsis. — J. Wildl. Manage. 71: 2084-2089.

Opermanis, O. (2004). Appearance and vulnerability of artificial duck nests to avian predators. - J. Avian Biol. 35: 410-415.

Orr, N. (1999). Egg-burying behaviour of Kentish plovers. — Br. Birds 92: 367-368.

Pereira, A.I. \& Amat, J.A. (2010). Nesting of the double-striped thick-knee (Burhinus bistriatus) in a hot environment. - Ornitol. Neotrop. 21: 149-154.

Pérez-Santigosa, N., Hidalgo-Vila, J. \& Díaz-Paniagua, C. (2003). Depredación y consumo de huevos de tritón pigmeo, Triturus pygmaeus en los medios acuáticos temporales de Doñana. — Rev. Esp. Herpetol. 17: 11-19. 
Prokop, P. \& Trnka, A. (2011). Why do grebes cover their nests? Laboratory and field tests of two alternative hypotheses. - J. Ethol. 29: 17-22.

Rahn, H. (1991). Why birds lay eggs. — In: Egg incubation: its effects on embryonic development in birds and reptiles (Deeming, D.C. \& Ferguson, M.W.J., eds). Cambridge University Press, Cambridge, p. 345-360.

Reid, J.M., Cresswell, W., Holt, S., Mellanby, R.J., Whitfield, D.P. \& Ruxton, G.D. (2002a). Nest scrape design and heat loss in pectoral sandpipers (Calidris melanotos). - Funct. Ecol. 16: 305-312.

Reid, J.M., Monaghan, P. \& Nager, R.G. (2002b). Incubation and the costs of reproduction. - In: Avian incubation: behaviour, environment, and evolution (Deeming, D.C., ed.). Oxford University Press, Oxford, p. 314-325.

Remeš, V. (2005). Nest concealment and parental behaviour interact in affecting nest survival in the blackcap (Sylvia atricapilla): an experimental evaluation of the parental compensation hypothesis. - Behav. Ecol. Sociobiol. 58: 326-333.

Saalfeld, S.T., Conway, W.C., Haukos, D.A. \& Johnson, W.P. (2011). Nest success of snowy plovers (Charadrius nivosus) in the southern High Plains of Texas. - Waterbirds 34: 389-399.

Sealy, S.G. (1995). Burial of cowbird eggs by parasitized yellow warblers: an empirical and experimental study. - Anim. Behav. 49: 877-889.

Shimoda, T., Shinkaji, N. \& Amano, H. (1994). Oviposition behavior of Oligota kashmirica benefica Naomi (Coleoptera: Staphylinidae). I. Adaptive significance of egg-covering behavior by adult females. - Jpn. J. Appl. Entomol. Zool. 38: 1-6.

Solís, J.C. \& de Lope, F. (1995). Nest and egg crypsis in the ground-nesting stone curlew Burhinus oedicnemus. — J. Avian Biol. 26: 135-138.

Summers, R.W. \& Hockey, P.A.R. (1981). Egg-covering behaviour of the white-fronted plover Charadrius marginatus. - Ornis Scand. 12: 240-243.

Szentirmai, I. \& Székely, T. (2004). Diurnal variation in nest material use by the Kentish plover Charadrius alexandrinus. - Ibis 146: 535-537.

Trnka, A., Prokop, P. \& Batáry, P. (2008). Dummy birds in artificial nest studies: an experiment with red-backed shrike Lanius collurio. - Bird Stud. 55: 329-331.

Valera, F., Hoi, H. \& Schleicher, B. (1997). Egg burial in penduline tits, Remiz pendulinus: its role in mate desertion and female polyandry. — Behav. Ecol. 8: 20-27.

Villemart, R.H. (2001). Egg covering behavior of the neotropical harvestman Promitobates ornatus (Opiliones, Gonyleptidae). — J. Arachnol. 29: 249-252.

Ward, D. (1990). Incubation temperatures of crowned, black-winged, and lesser black-winged plovers. - Auk 107: 10-17.

Weston, M.A. \& Elgar, M.A. (2005). Parental care in hooded plovers (Thinornis rubricollis). - Emu 105: 283-292.

Williams, J.B. (1996). Energetics of avian incubation. In: Avian energetics and nutritional ecology (Carey, C., ed.). Chapman and Hall, New York, NY, p. 375-416.

X-Rite (2000). A guide to understanding color communication. X-Rite, Grandville, MI. 